\title{
Impact and effectiveness in pregnant women of a collective meeting on Labour Epidural Analgesia (LEA)
}

\author{
Anaesthesia, Analgesia, Obstetrics
}

\author{
C. Beaucreux ${ }^{1}$, A. Le Gouez ${ }^{1}$, K. Bouattour ${ }^{1}$, F. J. Mercier ${ }^{1}$, M. Soued ${ }^{1}$ \\ ${ }^{1}$ Department of Anaesthesiology, Antoine Béclère Hospital - APHP \& School of Medicine, South \\ University of Paris - Clamart (France)
}

\section{BACKGROUND AND GOAL OF THE STUDY}

In France, each centre can choose the optimal way to inform about Labour Epidural Analgesia (LEA), including through collective meetings. This study aims to evaluate parturients' knowledge a priori, just after a collective briefing to estimate its effectiveness and long term recall after a free interval.

\section{PATIENTS AND METHODS :}

We conducted a prospective monocentric study from October 2015 to April 2016. Three identical selfquestionnaires were given to parturients at three different times

\section{Q1 : before the collective briefing}

Q2 : just after the briefing

Q3 : after a free interval, in the waiting room before the anaesthesia visit.

Each questionnaire consisted in 29 closed-ended questions divided into four parts related to LEA (general information, LEA risks, LEA procedure and LEA effectiveness).

Global rates of correct answers at each questionnaire were compared and subgroups analyses were performed to evaluate the impact of history of LEA, level of education and category of age. Due to non parametric distribution, Kruskal-Wallis tests were performed, followed by Wilcoxon tests with Holm correction when necessary. A $p<0.05$ was considered as level of significance

Results are expressed as median [interquartile range].

\section{RESULTS :}

We included 296 patients but only 93 answered the three questionnaires. Among these 93 parturients, global rates of correct answers were 45\% [35 - 55], 76\% [69-86] and $76 \%$ [66 - 83] at Q1, Q2 and Q3 respectively. Results were significantly better at Q2 and Q3, versus Q1 $(p<0.001)$; but there was no difference between $Q 2$ and $Q 3$ ( $p=$ $0.15)$. There was no significant influence of history of LEA on rates of correct answers $(p=0.08, p=0.67$ and $p=$ 0.41 at Q1, Q2 and Q3 respectively). Age and level of education only influenced rates of correct answers at Q3 : parturients in [31- 35 years] category had more correct answers than parturients in $[\leq 30$ years] category $(79 \%$ [72 - 86] vs. $69 \%[53-82]$ respectively, $p=0.02)$; and parturients in $[\geq \mathrm{A}$-level +5$]$ group responded better than those in $[<A-l e v e l+3]$ group $(79 \%[71-85]$ vs. $67 \%[62-$ 79] respectively, $p=0.03)$.

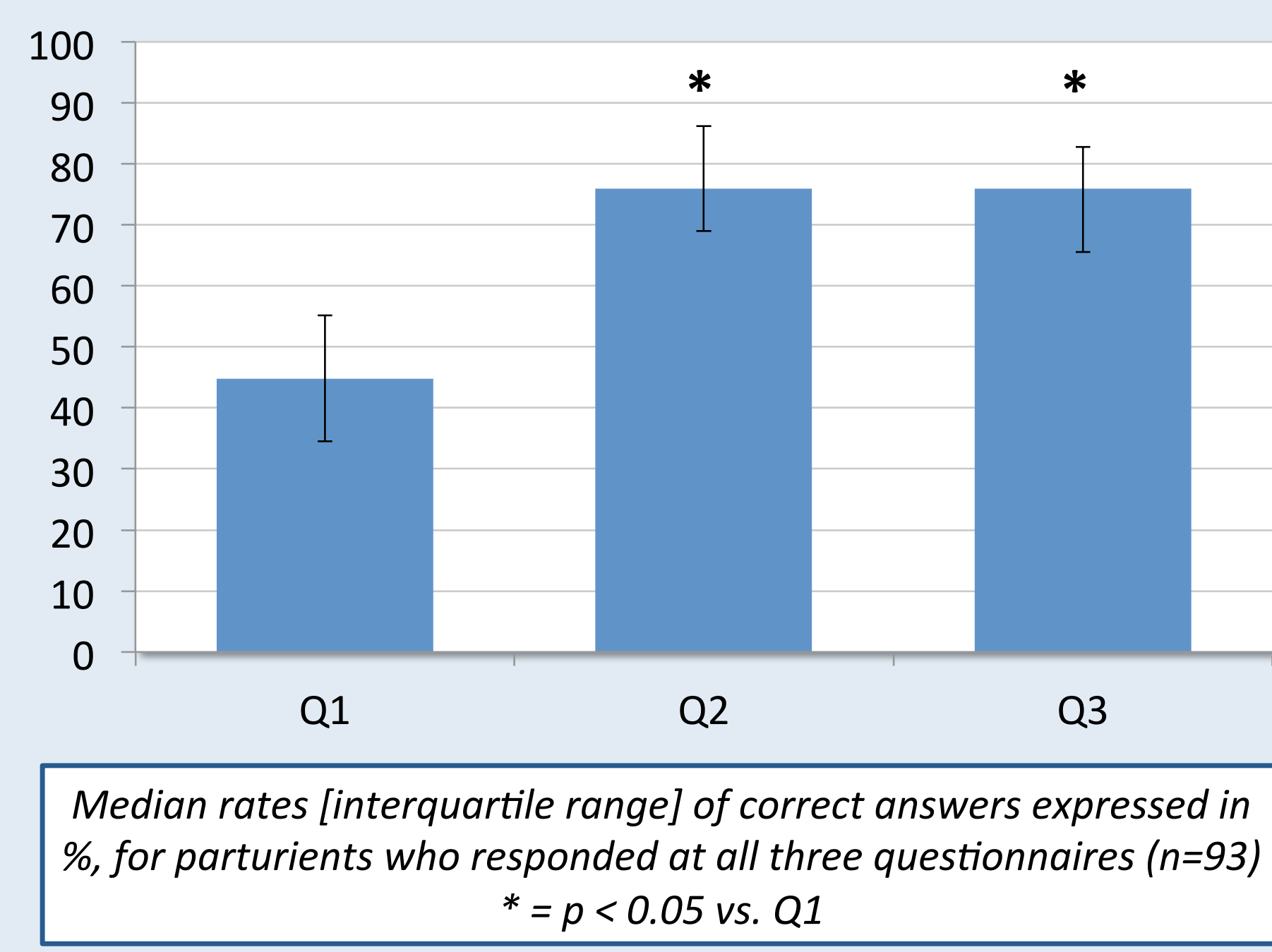

\section{CONCLUSION :}

The information provided during a collective briefing about LEA is relatively well understood and retained in the long term but remained perfectible. Adding a written information could be considered to improve the retention of information provided during the oral briefing. 